\title{
POST MENOPAUSAL BLEEDING
}

\author{
DR. SADIA ZULFIQAR CHEEMA \\ MBBS, FCPS, MRCOG \\ Senior Registrar OB-GYN Dept. \\ Services Hospital, Lahore \\ DR. MUHAMMAD IKRAM \\ MBBS, MCPS, FCPS \\ Senior Registrar OB-GYN Dept \\ Shaikh Zayed Medical Complex, Lahore
}

\author{
DR. ROOHI SAEED \\ MBBS, DA, MCPS, FRCOG \\ Associate Professor OB-GYN Dept \\ Shaikh Zayed Medical Complex, Lahore \\ Prof. Muhammad Saeed \\ MBBS, MD, FRCOG, MBA \\ Professor \& Head of Department OB-GYN \\ Shaikh Zayed Medical Complex, Lahore
}

\begin{abstract}
Objective: To find out the causes of postmenopausal bleeding and their correlation with medical illness. DESIGN: Single centre, cross sectional study. Place and duration: The department of obstetrics and gynaecology, Shaikh Zayed Postgraduate Medical Institute and hospital, Lahore from $1^{\text {st }}$ August 2000 to $30^{\text {th }}$ June 2002. Subjects and methods: All the patients with post menopausal bleeding diagnosed during the study periods were included, except patients after hysterectomy and premature menopause. Relative informations were filled in a Performa and informations were taken from case records. Results: Total 50 patients were included in the study. Maximum number of patients with postmenopausal bleeding were between $56-60$ years (32\%). Most of the patients were having parity between 4-6 (48\%). Majority of patients (32\%) had symptom about 10 years after menopause. Hypertension, diabetes and obesity were commonly found medical illness in these patients, especially when cause is endometrial carcinoma, ultrasound scan, Pap smear and endometrial biopsy are essential to rule out cause of post menopausal bleeding. $70 \%$ patients were having benign cause while $30 \%$ patients had malignant cause for post menopausal bleeding. Conclusion: Carcinoma of genital tract is one of the most important cause of postmenopausal bleeding, so early detection of the cases can be life saving. Detailed medical evaluation, aid of ultrasonography, Pap smear and endometrial biopsy is required to find the cause of postmenopausal bleeding.
\end{abstract}

Key words: $\quad$ Post menopausal bleeding, Pap Smear, Carcinoma

\section{INTRODUCTION}

The term menopause is derived from the Greek words menos (month) and pause (to stop). It means complete or permanent cessation of ovarian function and consequently menstruation. 
Menopause is the last menstrual bleed and it can be diagnosed retrospectively after one year of amenorrhoea ${ }^{1}$.

The average age of menopause is 51 years ${ }^{2}$. Any bleeding after menopause must be investigated promptly as it is the common presentation of endometrial and invasive cervical cancer. About $90 \%$ of patients with endometrial cancer present with postmenopausal bleeding, however $10 \%$ of patients with postmenopausal bleeding have endometrial cancer ${ }^{3}$.

Patients with endometrial hyperplasia can present with post menopausal or perimenopausal bleeding. Although cystic and adenomatous hyperplasia are rarely associated with endometrial carcinoma. But carcinoma may occur in $25-50 \%$ of cases with atypical hyperplasia.

A cervical smear and endometrial biopsy is required in all cases of postmenopausal bleeding. Survival of patients with endometrial cancer increases with early detection by endometrial curettage ${ }^{4}$. However curettage biopsy can fail in cases of polyp and cancer. The histopathology of hysterectomy specimen can confine the diagnosis.

A total number of 50 patients with postmenopausal bleeding were included in the study. A detailed history and examination was carried out. All the patients were investigated including complete examination of blood, blood sugar, renal function tests, x-ray chest, ECG and pelvic ultrasonography to assess the endometrial thickness and localize any ovarian pathology. Cervical cystology and cervical biopsies were done in suspicious cases. Dilatation and curettage was done under general anesthesia and specimen were sent for histopathology.

\section{AIM AND OBJECTIVES}

1. To find out common causes of postmenopausal bleeding.

2. To find out correlation between age, parity and medical illness with the causes of postmenopausal bleeding.

\section{STUDY DESIGN}

Retrospective study.

\section{PERIOD}

$1^{\text {st }}$ August 2000 to $30^{\text {th }}$ June 2002.

\section{SETTING}

Department of Obstetrics and Gynaecology at Shaikh Zayed Federal Postgraduate Medical Institute and Hospital, Lahore.

\section{PATIENTS \& METHODS}

50 cases records of postmenopausal women were studied.

\section{INCLUSION CRITERIA}

Patients with their last menstrual periods at least one year before their symptom of bleeding were selected from out patient department and emergency. Patients with postmenopausal blood stained discharge were also included.

\section{EXCLUSION CRITERIA}

Patients with hysterectomy and premature menopause (before 40 year of age) were not included in the study.

\section{METHODOLOGY}

Patient case records were reviewed from files and data was collected including age, parity, weight, menstrual history, past medical history, family history and drug history including hormone replacement therapy. Information about general, systemic examination and investigations including Pap smear, pelvic ultrasonography, fractional curettage and histopathology was taken.

\section{STATISTICAL ANALYSIS}

Simple statistical analysis of the data was done and results were tabulated.

\section{RESULTS}

In this study 50 numbers of patients with postmenopausal 
bleeding were included. Table-I shows that mean age of patients with post menopausal bleeding is 55.3 years. Maximum number of patients were between $56-60$ years i.e. 16 patients $(32 \%)$.

\begin{tabular}{|c|c|c|}
\hline \multicolumn{3}{|c|}{$\begin{array}{c}\text { Table-I. Age distribution in patients with post } \\
\text { menopausal bleeding ( } \mathbf{n}=50)\end{array}$} \\
\hline Age (years) & No. Of Pts. & \% age \\
\hline $45-50$ & 15 & 30 \\
\hline $51-55$ & 08 & 16 \\
\hline $56-60$ & 16 & 32 \\
\hline $61-65$ & 04 & 08 \\
\hline$>65$ & 07 & 14 \\
\hline \multicolumn{2}{|c|}{ Mean age $55.3 \pm 2.55$ years } \\
\hline
\end{tabular}

Table-II is regarding parity, most of the patients had parity between 4-6 (48\%). Only 2\% patients were nullipara.

\begin{tabular}{|l|c|c|}
\hline \multicolumn{3}{|c|}{ Table-Il. Reproductive status of patients with post } \\
menopausal bleeding (n=50)
\end{tabular}

Table-III shows that $42 \%$ of patients had postmenopausal bleeding 10 years after menopause and only $20 \%$ had symptom within 5 years of menopause.

\begin{tabular}{|c|c|c|}
\hline \multicolumn{3}{|c|}{ Table-III. Age distribution in patients with post } \\
menopausal bleeding. \\
\hline Time (years) & No. Of Pts. & $\%$ age \\
\hline$<5$ & 10 & 20 \\
\hline $6-10$ & 19 & 38 \\
\hline$>10$ & 21 & 42 \\
\hline \multicolumn{3}{|c|}{ Mean age $8.2 \pm 0.23$} \\
\hline
\end{tabular}

Table-IV is about association of medical illness with postmenopausal bleeding. Hypertension and diabetes were found to be the most common medical illnesses.

\begin{tabular}{|l|c|c|}
\hline \multicolumn{2}{|c|}{$\begin{array}{c}\text { Table-IV. Associated medical illness in patient with post } \\
\text { menopausal bleeding ( } \mathbf{n = 5 0}\end{array}$} \\
\hline Medical illness & No. Of Pts. & \%age \\
\hline Hypertension & 15 & 30 \\
\hline Diabetic & 08 & 16 \\
\hline Obesity & 16 & 32 \\
\hline Other & 04 & 08 \\
\hline No disease & 07 & 14 \\
\hline \multicolumn{2}{|c|}{ *total varies due to multiple illnesses. } \\
\hline
\end{tabular}

Table- $V$ is showing that every patient with endometrial carcinoma was having either one or more medical illnesses.

Table-VI shows ultrasonographic finding in patients with postmenopausal bleeding. Endometrial thickness was the most important parameter. It was $>5 \mathrm{~mm}$ in $46 \%$ patients.

Table-VII and VIII are about the method of diagnosing the causes of postmenopausal bleeding. In this study main method was fractional curettage and Pap smear was done in 40 cases. 


\begin{tabular}{|l|c|c|}
\hline \multicolumn{3}{|c|}{ Table-V. Percentage of medical illness in patients with Ca. } \\
Endometrium (n=5)
\end{tabular}

\begin{tabular}{|c|c|c|}
\hline USG & No. Of Pts. & \%age \\
\hline $\begin{array}{l}\text { 1. Uterine size } \\
\text { Atrophic } \\
\text { Normal } \\
\text { Enlarged }\end{array}$ & $\begin{array}{l}42 \\
10 \\
22 \\
10\end{array}$ & $\begin{array}{l}20 \\
44 \\
20\end{array}$ \\
\hline $\begin{array}{l}\text { 2. Endometrial thickness } \\
\leq 5 \mathrm{~mm} \\
\geq 5 \mathrm{~mm}\end{array}$ & $\begin{array}{l}42 \\
19 \\
23\end{array}$ & $\begin{array}{l}38 \\
46\end{array}$ \\
\hline $\begin{array}{l}\text { 3. Ovarian size } \\
\text { Normal } \\
\text { Cyst/mast }\end{array}$ & $\begin{array}{c}42 \\
7 \\
35\end{array}$ & $\begin{array}{l}14 \\
70\end{array}$ \\
\hline $\begin{array}{l}\text { 4. Fluid in cul-delsac } \\
\text { Seen } \\
\text { Not seen }\end{array}$ & $\begin{array}{l}42 \\
02 \\
40\end{array}$ & $\begin{array}{l}04 \\
80\end{array}$ \\
\hline
\end{tabular}

\begin{tabular}{|l|c|c|}
\hline \multicolumn{2}{|c|}{ Table-VII. Method diagnosing the cause of post } \\
menopausal bleeding $(\mathbf{n = 5 0})$
\end{tabular}

\begin{tabular}{|l|c|c|}
\hline \multicolumn{3}{|c|}{$\begin{array}{c}\text { Table-VIII. Results of cervical screening in patients with } \\
\text { post menopausal bleeding ( } \mathbf{n}=50)\end{array}$} \\
\hline Pap smear & No. Of Pts. & \%age \\
\hline Inflammatory change & 34 & 68 \\
\hline Malignant change & 02 & 04 \\
\hline Not done & 10 & 20 \\
\hline Inadequate & 04 & 08 \\
\hline \multicolumn{2}{|c|}{${ }^{*}$ total varies due to multiple illnesses. } \\
\hline
\end{tabular}

Table-IX gives detail of all the causes of postmenopausal bleeding. 30\% patients were having malignant cause while $70 \%$ were having benign causes. Out of malignant causes cervical carcinoma was the most common i.e. $14 \%$.

\section{Table-IX. Histopathological finding $(n=50)$}

\begin{tabular}{|c|c|c|}
\hline & No. Of Pts. & $\%$ age \\
\hline \multicolumn{3}{|l|}{ Benign cause } \\
\hline Benign polyps & 08 & 16 \\
\hline Atrophic endometrium & 16 & 32 \\
\hline Proliferative endometrium & 04 & 08 \\
\hline Secretary endometrium & 07 & 14 \\
\hline \multicolumn{3}{|l|}{ Endometritis } \\
\hline Simple hyperplasia & 01 & 02 \\
\hline \multicolumn{3}{|l|}{ Adenomatous hyperplasia } \\
\hline \multicolumn{3}{|l|}{ Leiomyoma } \\
\hline \multicolumn{3}{|l|}{ Insufficient } \\
\hline \multicolumn{3}{|l|}{ Lichenoid lesion } \\
\hline \multicolumn{3}{|l|}{ Malignant } \\
\hline Endometrial carcinoma & 05 & 10 \\
\hline Cervical carcinoma & 07 & 14 \\
\hline Ovarian carcinoma & 03 & 06 \\
\hline
\end{tabular}




\section{DISCUSSION}

The incidence of postmenopausal bleeding decreases with increasing age while the probability of cancer as the underlying cause increases ${ }^{5}$. The mean age of patients with endometrial cancer is 61 years with $80 \%$ of women being postmenopausal 1 . This study also shows that mean age of patients with endometrial cancer is 61.2 years.

The risk of endometrial carcinoma in women with postmenopausal bleeding rises with age from about $1 \%$ at the age of 50 years to about $25 \%$ at the age of 80 years ${ }^{6}$. In our study out of 5 patients of endometrial carcinoma 3 were $>65$ years of age.

Nulliparity associated with anovulation is considered a risk factor for endometrial cancer. The parity in our patients with endometrial cancer ranged between 2-10 and there was no nulliparous woman with endometrial cancer. A reduction in risk (of borderline significance) is observed in parous women but there is no evidence for the risk to decline with increasing number of births ${ }^{7}$.

Diabetes, obesity and hypertension are common medical illnesses in patients with postmenopausal bleeding. These are risk factors for endometrial cancer.

In one study the odds ratio form endometrial malignancy was 9.1 for women over 70 years, 37 for women with diabetes and 2.7 for nulliparous women 9 .

In this study, 4 patients with endometrial carcinoma were hypertensive and 2 patients were obese and only one patient was diabetic. Some patients were having more than one medical illness.

On the basis of clinical information obtained on history and physical examination, diagnosis can be made in a few cases. In most of the cases diagnosis requires aid of investigations. Until recently, fractional curettage under general anesthesia has been advocated as the investigation of choice for women with postmenopausal bleeding. ${ }^{5,10}$ Ultrasound scan has an important role in the evaluation of patient with postmenopausal bleeding by measuring the endometrial thickness and adenxal masses.

The best evidence recently available suggests that full double thickness measurements which include the contents of the cavity should be made using a transvaginal probe ${ }^{11}$.

In our study with cut off level of $5 \mathrm{~mm}, 38 \%$ patients showed endometrial thickness of $5 \mathrm{~mm}$ or less and finding was mainly in patients with atrophic endometrium. Patients having endometrial thickness more than $5 \mathrm{~mm}$ were $46 \%$ and were of malignancy, hyperplasia and of young age group. In a study by Nasli and Coast in 1989, where they compared the ultrasound findings and endometrial pathology in postmenopausal women found that sensitivity of ultrasound to diagnose endometrial pathology was $91 \%$ and all endometrial carcinoma, hyperplasia and pyometrias were diagnosed. In this study finding of endometrium greater than $5 \mathrm{~mm}$ in thickness was highly suggestive of underlying pathology ${ }^{12}$.

The probability of cancer is extremely low if a clear symmetrical endometrial strip measuring less than $4 \mathrm{~mm}$ in thickness is seen in ultrasound particularly in the context of an isolated episode of postmenopausal bleeding. If endometrial thickness is $>5 \mathrm{~mm}$ then endometrial biopsy is indicated. Our study also support this reference ${ }^{13}$.

Gredmark et al found that 8 out of 457 women who presented with abnormal postmenopausal vaginal bleeding had ovarian tumour. As many ovarian cancer cannot be palpated on bimanual examination so ultrasonography provides the opportunity to examine whole pelvis ${ }^{14}$.

Pap smear has an important role in the evaluation of the patients with postmenopausal bleeding, some argue that abnormal uterine bleeding in a menopausal women is a clinical indication for cervical cytology, irrespective of when last performed. Endometrial carcinoma may be detected by cervical cytology up to $30 \%$ of cases. In our 
study Pap smear showed malignant changes in only two cases.

Hysteroscopy and endometrial sampling is the standard method for diagnosis but in our hospital the endometrial tissue for histopathology was collected by dilatation and curettage under general anaesthesia in $50 \%$ of cases. $26 \%$ patients directly underwent hysterectomy because they were not willing to have two separate procedures, and clinically they were diagnosed as having benign cause. $6 \%$ patients have laparotomy and biopsy as they were diagnosed as case of ovarian tumour on ultrasonography.

In our study $14 \%$ patients were confirmed as having cervical carcinoma on histopathology after cervical biopsy. The most common malignant non-endometrial cause of postmenopausal bleeding is carcinoma of cervix with reported incidence in women with postmenopausal bleeding of $0.8-13 \% \%^{6,15,16}$. Recent reports suggests that the incidence of endometrial carcinoma to be $1.5-28 \%$ with an average of $11 \%$, 12 In our study incidence of endometrial carcinoma was $10 \%$. Out of 50 patients, 3 patients were having ovarian carcinoma. So a total of 15 patients i.e. $30 \%$ were having malignant cause of postmenopausal bleeding and 35 patients $(70 \%)$ were having benign cause. Payne et al found benign or nonneoplastic causes for postmenopausal bleeding in $66 \%$ of women ${ }^{15}$.

In the study of Gredmark, endometrial histopathology showed atrophy $50 \%$, proliferation $4 \%$ secretary $1 \%$, polyp $9 \%$, different degree of hyperplasia $10 \%$, adenocarcinoma $8 \%$, non representative $14 \%$ and other disorders $3 \%$. In our study atrophic endometrium was just in $30 \%$, proliferation $12 \%$. Secretary in $6 \%$, polyp in $12 \%$, simple hyperplasia in $2 \%$. Other disorders $4 \%$ out of all the $70 \%$ benign cause of post menopausal bleeding, while $4 \%$ samples were insufficient. These findings differ from the findings conducted by Shamsa Akhtar in 1996, who found $26.36 \%$ cases of different types of hyperplasia, $19.46 \%$ cases with carcinoma of endometrium, $15.27 \%$ with carcinoma of cervix, $13.89 \%$ cases with inadequate sample and $9.72 \%$ with atrophic endometrium ${ }^{17}$.

In this study treatment of postmenopausal bleeding was according to the cause.

\section{CONCLUSION}

This study has the following conclusive findings..

1. Majority of cases i.e. $70 \%$ were having benign cause.

2. Malignancy was very important cause of postmenopausal bleeding. It constitutes $30 \%$ of cases.

3. More patients of malignant disease were of carcinoma cervix i.e. $14 \%$ as compared to carcinoma endometrium which was $10 \%$

4. Suspicion of endometrial carcinoma increases if postmenopausal bleeding is associated with other cofactors like medical illness (hypertension, diabetes, obesity).

5. Ultrasonography, Pap smear and endometrial biopsy are essential to diagnose cause of postmenopausal bleeding.

\section{REFERENCE}

1. Soutter WP. Malignant disease of the uterus. Dewhurst's text book of obstetrics and gynaecology $6^{\text {th }}$ edition Bodmin cornwall, UK 1999;560-71.

2. Khadija, Asaf $H$, samina Hamid. Causes of post menopausal bleeding. Pak J Obstet \& Gynaecol 10(3):22-26.

3. Wong SF, Luk KL, Wing ayk, Tang LCH. Finding in the women with post menopausal bleeding investigated with hysteroscopy. J of Obstet and gynaecol $2001 ; 21(4) 392-95$.

4. Fleischer AC, Didley DS, Entman SS, Baxter JW, Klumiris $G C$, James $A E$. Myometrial invasion by endometrial carcinoma: sacographic assessment. Radiology 1987;162:307-10.

5. Monaghan JM, operation on the uterine cavity. In: monagham JM (ed) Bonney's gynaecological surgery $9^{\text {th }}$ Ed. East Sussex: Bailliere Tindall 1986;40-43.

6. Gredmark $T$, Kvint $S$, havel $G$, Mattsson LA. 
Histopathological findings in women with post menopausal bleeding. $\mathrm{Br} J$ Obstet Gynaecol1995; 102:133-36.

7. Parazzini F, Vecchia CL, Negri E, Fedel L, Balotta F. Reproductive factors and risk of endometrial cancer. Am J obstet gynaecol 1991;164:522-27.

8. Pace S, Grassi A, Ferrero S. Diagnostic methods of early detection of endometrial hyperplasia and cancer. Int. J Gynaecol Oncol 1995;5:373-81.

9. Feldman S, Shapter a, Welch WR, Berkowitz RS. Two year follow up of 263 patients with post perimenopausal vaginal bleeding and negative initial biopsy. Gynaecol oncol 1994;55:56-59.

10. Peel KR. Malignant disease of the uterine body. In: Whitfield CR ed. Dewhurst's text book of obstetrics and gynaecology for postgraduates, $5^{\text {th }}$ ed London: Black well science 1995;747-58.

11. Tsuda H, Kawabata M, Kawabata K. Difference between occidental and oriental post menopausal women in cut off level of endometrial thickness for endometrial cancer screening by vaginal scan. Am J obstet gynaecol 1995;172:1494-95.
12. Nasri MN, Coast GJ. Correlation of ultrasound findings and endometrial histopathology in post menopausal women. Br J obstet gynaecol 1989;96:1333-38.

13. Briby M, Lindsell DR. the role of transvaginal ultrasound in the investigation of women with PMB. Clin Radiol 1998;53:502-5.

14. Andolf $E$, Snalemius $F$, Astedf $B$. Ultrasonography for early detection of ovarian carcinoma. $\mathrm{Br} \mathrm{J}$ obstet gynaecol 1986;93:1286-89.

15. Payne FL, Wright RC, Fettaman HH. Post menopausal bleeding. Am J obstetr gynaecol 1959;77:1216-27.

16. Granberg S, Wikland M, Karlsson B, Norstrom A, Friberg LG. Endometrail thickness as measured by endovaginal ultrasonography for identifying endometrial abnormality. Am $\mathrm{J}$ obstet gynaecol 1991;164:47-52.

17. Akhtar S. histopathological finding following curettage in women with post menopausal bleeding. Paper presented in $1^{\text {st }}$ conference of obstetrics and gynaecology of SAARC countries 1996.

\section{READING MAKETH A FULL MAN; CONFERENCE A READY MAN; AND WRITING AN EXACT MAN}

Bacon 